\title{
Turbocharger Matching Method for Reducing Residual Concentration in a Turbocharged Gasoline Engine
}

\author{
Author, co-author (Do NOT enter this information. It will be pulled from participant tab in \\ MyTechZone) \\ Affiliation (Do NOT enter this information. It will be pulled from participant tab in MyTechZone)
}

Copyright @ 2015 SAE International

\begin{abstract}
In a turbocharged engine, preserving the maximum amount of exhaust pulse energy for turbine operation will result in improved low end torque and engine transient response. However, the exhaust flow entering the turbine is highly unsteady, and the presence of the turbine as a restriction in the exhaust flow results in a higher pressure at the cylinder exhaust ports and consequently poor scavenging. This leads to an increase in the amount of residual gas in the combustion chamber, compared to the naturally-aspirated equivalent, thereby increasing the tendency for engine knock. If the level of residual gas can be reduced and controlled, it should enable the engine to operate at a higher compression ratio, improving its thermal efficiency.
\end{abstract}

This paper presents a method of turbocharger matching for reducing residual gas content in a turbocharged engine. The turbine is first scaled to a larger size as a preliminary step towards reducing back pressure and thus the residual gas concentration in-cylinder. However a larger turbine causes a torque deficit at low engine speeds. So in a following step, pulse separation is used. In optimal pulse separation, the gas exchange process in one cylinder is completely unimpeded by pressure pulses emanating from other cylinders, thereby preserving the exhaust pulse energy entering the turbine. A pulse-divided exhaust manifold enables this by isolating the manifold runners emanating from certain cylinder groups, even as far as the junction with the turbine housing.

This combination of appropriate turbine sizing and pulse-divided exhaust manifold design is applied to a Proton 1.6-litre CamPro CFE turbocharged gasoline engine model. The use of a pulse-divided exhaust manifold allows the turbine to be increased in size by 2.5 times (on a mass flow rate basis) while maintaining the same torque and power performance. As a consequence, lower back pressure and improved scavenging reduces the residual concentration by up to $43 \%$, while the brake specific fuel consumption improves by approx. $1 \%$, before any modification to the compression ratio is made.

\section{Introduction}

Many efforts have been made globally to reduce greenhouse gasses, particularly the $\mathrm{CO}_{2}$ emissions produced by motor vehicles. Based on a study of global atmospheric trace gases by the Carbon Dioxide Information Analysis Center (CDIAC), $\mathrm{CO}_{2}$ has increased from 280ppm pre-1750 to 386ppm in 2009, an increase of 106ppm. Modern road vehicles are required to meet stringent emission and fuel economy requirements, and several emission standards for Page 1 of 9 passenger cars are already established or are currently being proposed to tackle climate change, and some are in the process of revision. For example, the European Commission aims to reduce $\mathrm{CO}_{2}$ emissions from light-duty vehicles to a level of $95 \mathrm{~g} / \mathrm{km}$ by 2020 [1]. As a consequence, researchers and manufacturers have been investigating advanced technologies to meet these demands. One method that can be viewed as a viable short-to-medium term solution [2] is to use a smaller capacity engine that has lower heat and frictional losses, but still provides the power of a larger engine, by using a forced induction system - this is called 'engine downsizing'. Forced induction systems based on turbochargers play a very important role in engine downsizing and are arguably the most practical and economical method to address the fuel economy and emissions challenges for transport.

With downsized turbocharged engines becoming increasingly widely used, the focus is now on how to further increase the efficiency of the engine for improved fuel economy and better engine transient response. Research efforts can be broadly split between work on maximizing work extraction by the piston and recovering energy from the exhaust [3]. Preserving the maximum amount of exhaust pulse energy will result in increased turbine power and energy transfer to the compressor, hence faster turbocharger acceleration and thus improved engine transient response. However, the presence of higher pressure at the cylinder exhaust ports drives greater pumping work, while the consequent poor scavenging leads to an increase in the amount of residual gas in the cylinder, thereby increasing the tendency for engine knock [4].

One of the ways to mitigate the propensity for knock is to increase effective turbine size by raising the ratio of the throat area to radius (A/R) of the turbine, which reduces back pressure and thus the residual gas concentration in the cylinders. However, a larger turbine causes slower transient response, especially at low engine speeds. Therefore, pulse separation is proposed. In optimal pulse separation, the gas exchange process in one cylinder is not disturbed by pressure pulses emanating from other cylinders, thereby preserving the exhaust pulse energy entering the turbine. This paper describes a turbocharger matching method that combines pulse separation and optimal turbine matching to preserve exhaust pulse energy and reduce residual concentration for a turbocharged gasoline engine.

Much research on the effects of turbocharging the internal combustion engines has been carried out over many decades. Some studies have shown that while an appropriate turbocharger selection increases the power of the engine [5, 6], engine performance can be negatively affected (reducing power, torque, and increasing the 
pollutants emitted to the environment [7]), if the process is not carried out correctly. A typical turbocharger matching exercise in a 1D simulation environment is given by Pohorelsky et al. [8]. The required charge pressure is varied by sweeping the inlet pressure and exhaust back pressure within a certain range. From this, the initial sizing of the compressor can be performed. Different curve fitting methods for compressor and turbine performance characteristics are presented by Moraal et al. [9]. The efficiency and turbocharger speed are interpolated from the compressor maps. With efficiency defined, the power required by each compressor can be calculated. The compressor choice is then a complex balance between minimizing power consumed and the ability to keep an adequate margin to the limits of stable operation for all speeds. Korakianitis et al. [10] carried out a theoretical matching method for selecting a turbocharger for a given engine. They selected a range of turbochargers using theoretical relations, but recommended the final selection can only be obtained by experimental tests.

The residual gas fraction quantifies the burned gases that remain trapped inside the engine cylinders, which is caused by two mechanisms: the flow of burned gas from the exhaust manifold back to the engine cylinder during valve overlap, and the trapped gas in the cylinder just before the start of the valve overlap flow. High levels of residual gas is a prevalent factor for engine knock [4], which in spark-ignition engines is a phenomenon whereby the air-fuel mixture spontaneously combusts prior to spark plug ignition. This causes higher thermal and mechanical stresses that promote greater risk of mechanical failure of the piston or cylinder head. The main reason for the occurrence of knock is the high temperatures and pressures during the combustion process causing the end gas to auto ignite. Residual exhaust gases that have not left the cylinder also impact the composition of the fresh charge.

The amount of residual gas highly depends on the intake and exhaust processes. Galliot et al. [11] conducted an experiment to measure the residual gas fraction using a fast-response flame ionization hydrocarbon detector, which enabled measurement of in-cylinder hydrocarbon concentration in real time. According to their study, the residual gas content decreases with the increase of intake pressure. When the intake pressure equals the exhaust pressure, there would be very little back flow of the burned gas from the exhaust port. Fox et al. [12] also show that positive scavenging, when the intake pressure is greater than the exhaust pressure, causes a reduction in the residual gas fraction. Improving the pressure ratio (inlet pressure to exhaust pressure) from 0.3 to 1.0 , the residual gas fraction reduces from $25 \%$ to $10 \%$. Fox et al. also show that the valve overlap flow contributes to the amount of residual gas fraction. The effort to investigate the influence of residual gas on engine knock has been studied by Westin et al. [13]. According to this study, for constant ignition timing, greater residual gas fraction will increase the average cylinder pressure and temperature in the combustion chamber and consequently the engine is more likely to knock. Lower residual gas fraction also enables ignition timing to be advanced hence reducing the cylinder pressure and temperature. Reducing $15 \%$ of residual gas fraction when knock intensity is constant at $30 \mathrm{kPa}$ allows the ignition timing to be advanced up to $5 \mathrm{CAD}$, which improves the efficiency of combustion.

Exhaust valve modulation concepts such as Divided Exhaust Period (DEP) [14-17] and Valve-Event Modulated Boost (VEMB) [18,19] direct the highest energy exhaust flow from the cylinder into a blow down manifold, which is connected to the turbocharger turbine, and the lower energy exhaust flow into a scavenging manifold, which bypasses the turbine. This arrangement helps to reduce the back pressure experienced by the piston during scavenging, with the pumping work reduced as a consequence. Although the DEP and VEMB concepts are not directly relevant to this paper, their ability to decrease back pressure supports the reduction of in-cylinder residual concentration.

This review provides a brief insight into recent developments and the state-of-the-art of the topics at hand. In the next section, the proposed matching methodology for the reduction of exhaust back pressure, and thus the reduction of in-cylinder residuals and pumping losses, will be outlined.

\section{Methodology}

\section{Engine modelling}

The Proton 1.6L CamPro CFE turbocharged gasoline engine with the specification given in Tab. 1 was used as the baseline engine in this study. An engine model was constructed in the commercial 1D engine simulation tool GT-POWER software [20] and validated against engine dynamometer measurements. A simplified layout of the engine with the main measurement locations is shown in Fig. 1. Combustion heat release was modelled using an SI-Wiebe function, imposing the values of burn point and duration for all engine speeds at wide open throttle (WOT), this data having been obtained from performance and emissions testing by the Proton engine development team. Intake and exhaust valve lift and timing are defined according to the actual engine set-up. The values of intake and exhaust discharge coefficient were obtained during a flow bench test of CamPro cylinder head. Both the intake and exhaust manifolds are based on actual geometries from 3D CAD data.

Table 1. Proton 1.6L CamPro CFE engine specification.

\begin{tabular}{|l|l|}
\hline Combustion system & 4-stroke, in-line, gasoline PFI \\
\hline Capacity & 1.6 liters \\
\hline Compression ratio & 9.0 \\
\hline Bore x stroke & $76 \mathrm{~mm} x$ 86mm \\
\hline Induction system & Single-stage turbocharger \\
\hline Maximum torque & $205 \mathrm{Nm} @$ @ 2000-4000 rpm \\
\hline Maximum power & $103 \mathrm{~kW} @ 5000 \mathrm{rpm}$ \\
\hline Intake cam profile & $\leq 220^{\circ}$ (duration) / 7.51 mm (valve lift) \\
\hline Exhaust cam profile & $2^{\circ} \mathrm{BTDC} @ 0.15 \mathrm{~mm}$ lift \\
\hline
\end{tabular}
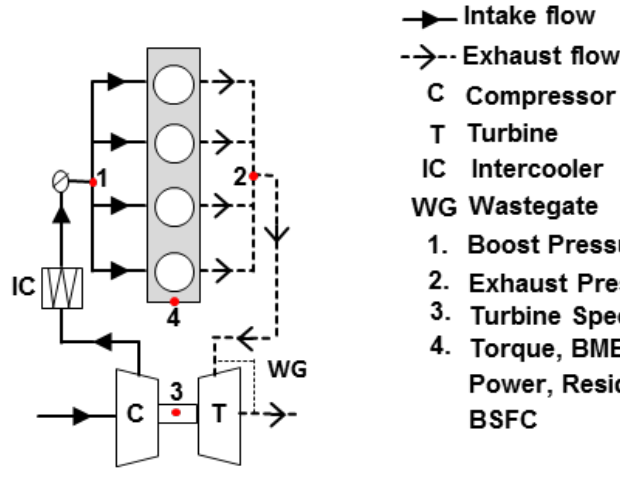

1. Boost Pressure

2. Exhaust Pressure

3. Turbine Speed

4. Torque, BMEP, Power, Residuals and BSFC

Page 2 of 9 
The baseline engine was simulated for 12 constant engine speeds between 1000-6500 rpm at 500 rpm intervals. As is standard for simulations of this kind, the steady state performance maps for the compressor and turbine obtained from the turbocharger supplier were applied, and the engine model was configured to converge on the specified torque target for each engine speed by using the in-built turbocharger wastegate controller. The function of a wastegate is to regulate the boost pressure delivered by the turbocharger. If the intake manifold boost pressure is higher than required at any given operating point, the wastegate opens and bypasses some exhaust gas flow around the turbine wheel (Fig. 2) [21]. This inhibits the torque developed by the turbine, consequently decelerating the turbocharger and thus reducing the boost pressure.

It should be noted that the supplier turbine maps were measured with the wastegate closed, which is typical industry practice. It is known, however, that opening the wastegate (in order to control boost) has a detrimental effect on turbine swallowing capacity [22, 23], in excess of that attributable to the bypass flow. In other words, for a given pressure ratio, the mass flow through a turbine with open wastegate is somewhat less than the sum of the separately measured mass flows through the turbine wheel and the wastegate. This phenomenon is not yet taken into account in the present methodology.

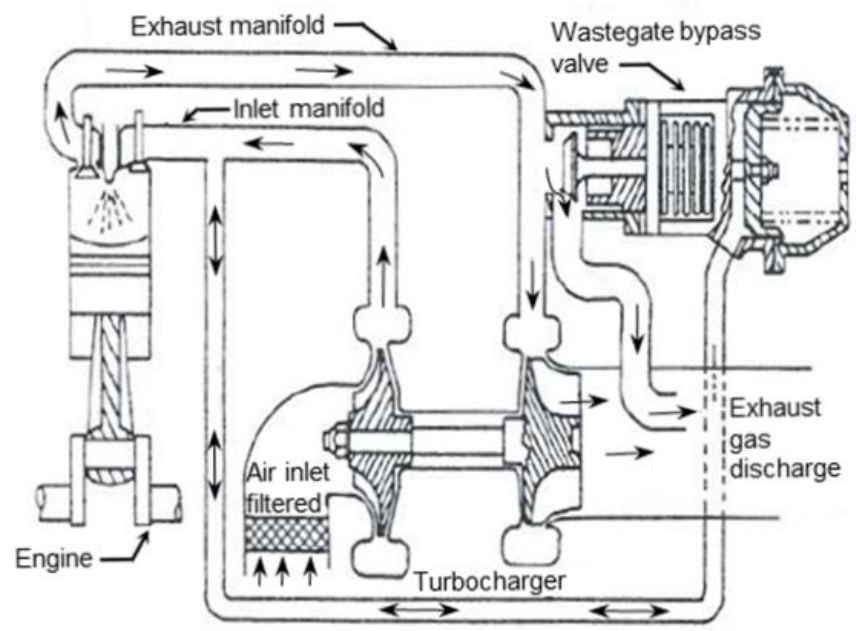

Figure 2. Configuration of a pneumatic wastegate for controlling boost [21].

The exhaust manifold has been discretized using the GT-POWER integrated software, GEM3D. The advantage of using GEM3D is that it maintains consistency of conversion between 3D and 1D geometry. Figure 3 illustrates the main steps in process of discretizing the Proton 1.6L CamPro exhaust manifold.

The GT-POWER engine model is then validated against test data. All the results in this paper have been normalized by the corresponding maximum value in each set of results. Torque and power results are shown in Fig. 4, which just confirms the specified performance target was met. By comparison with other measured engine test parameters (volumetric efficiency, BSFC, intake manifold pressure and temperature, and pre-catalyst pressure), Tab. 2 shows that a satisfactory validation of the baseline engine model was achieved; a key parameter is the intake manifold pressure and this was matched within an average error of less than $5 \%$ at all engine speeds $(<1 \%$ over the engine speed range 2500-5000 rpm).
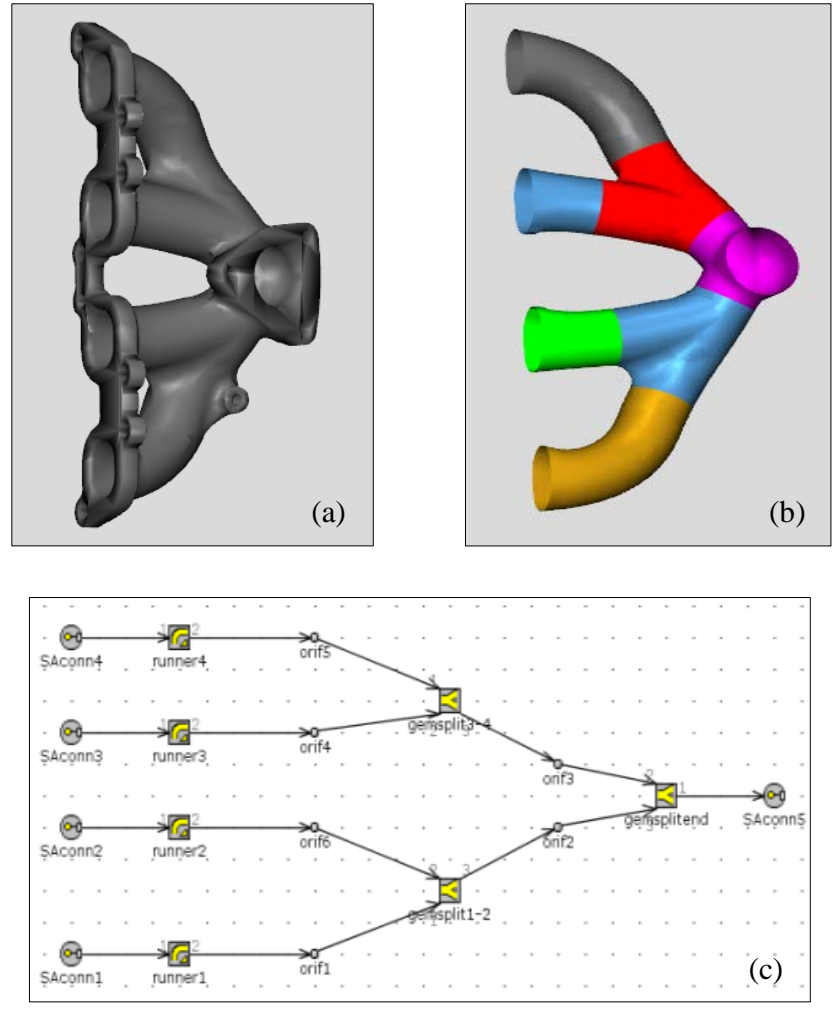

Figure 3. (a) Exhaust manifold in 3D CAD, (b) discretization in GEM3D, and (c) the resulting 1D layout in GT-POWER.

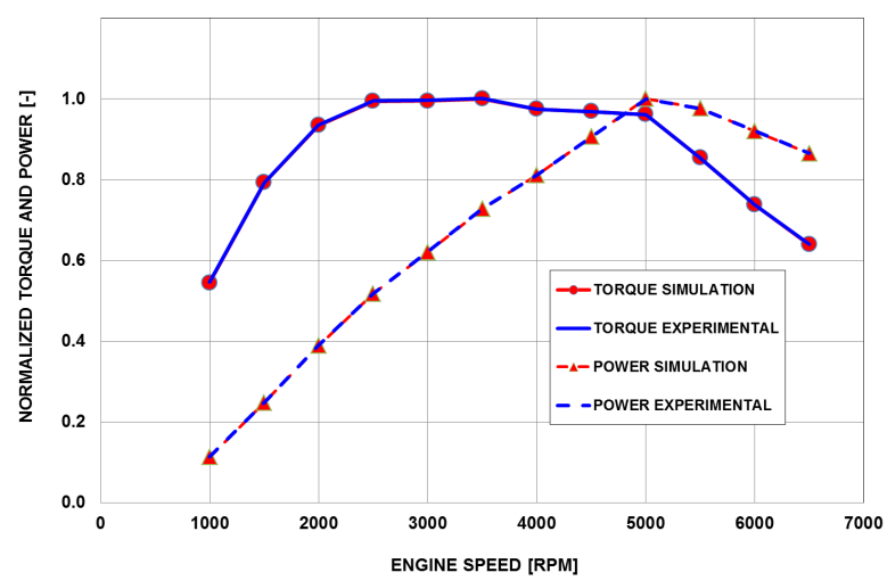

Figure 4. Confirmation that the engine simulation meets the target measured engine performance. 


\begin{tabular}{|c|c|c|c|c|c|}
\hline $\begin{array}{c}\text { Engine } \\
\text { speed } \\
\text { [rpm] }\end{array}$ & $\begin{array}{c}\text { Vol. eff. } \\
(\%)\end{array}$ & $\begin{array}{c}\text { BSFC } \\
(\%)\end{array}$ & $\begin{array}{c}\text { Intake } \\
\text { manifold } \\
\text { pressure } \\
(\%)\end{array}$ & $\begin{array}{c}\text { Pre- } \\
\text { catalyst } \\
\text { pressure } \\
(\%)\end{array}$ & $\begin{array}{c}\text { Intake } \\
\text { manifold } \\
\text { temp. } \\
(\%)\end{array}$ \\
\hline 1000 & -0.20 & -2.53 & -4.22 & 1.62 & 0.42 \\
\hline 1500 & -2.69 & -2.66 & -4.78 & 2.01 & -0.27 \\
\hline 2000 & 0.21 & 1.29 & -2.15 & 1.74 & -0.92 \\
\hline 2500 & 0.07 & 0.62 & -0.75 & 0.13 & -0.69 \\
\hline 3000 & 1.95 & 0.87 & 0.70 & -0.11 & 0.04 \\
\hline 3500 & 3.05 & -0.95 & 0.74 & -0.29 & 0.35 \\
\hline 4000 & 3.66 & -0.03 & 0.91 & -0.68 & -0.41 \\
\hline 4500 & 3.40 & -2.06 & 0.71 & -1.20 & -0.96 \\
\hline 5000 & 3.02 & -0.36 & 0.73 & -2.80 & -1.75 \\
\hline 5500 & 4.12 & -0.59 & 4.17 & -1.89 & -2.32 \\
\hline 6000 & 1.21 & -1.91 & 4.41 & -3.29 & -3.12 \\
\hline 6500 & 1.46 & 1.24 & 4.02 & -3.07 & -4.40 \\
\hline
\end{tabular}

\section{Turbine Sizing}

After validating the baseline engine model, the first step in the matching methodology is to set the turbine to a larger size. The primary aim of this step is to reduce back pressure and thus the residual gas concentration in the engine cylinders. Increasing the turbine area reduces the amplitude of the exhaust pressure pulse. While this lowers exhaust back pressure, it also reduces the specific energy available at the turbine [5].

Scaling of turbine size was achieved using the mass multiplier available in the turbine component in GT-POWER. This simply multiplies the mass flow rate across the whole turbine map while maintaining the values of pressure ratio, speed and efficiency. Although somewhat unrealistic (in reality turbine efficiency will gradually improve with size, for example), this has the advantage of isolating the effect of size on the specific energy available to accelerate the turbine. Furthermore, this approach permits the scaling to be continuous, instead of being limited to a fixed number of discrete size options as would be dictated by using real turbine maps.

Scaling of the turbine will eventually require a larger turbine (and compressor) wheel, with an associated increase in inertia - which will impact transient response. However, it will be possible to achieve a certain range of flow characteristics by scaling just the turbine housing $\mathrm{A} / \mathrm{R}$, without a change in wheel. Strictly speaking, it is within this constraint that the mass multiplier method should be used. To illustrate this, Fig. 5 shows the baseline turbine map (black squares) with the 12 engine operating points overlaid for mass multipliers of 1.0 (red circles) and 1.5 (green triangles). For the latter, the 1000 and 1500 rpm engine operating points still lie below the choking mass flow parameter of the baseline turbine - indicating that between 1000-1500 rpm, a mass multiplier of 1.5 may be enacted by enlarging the housing $A / R$, but does not necessarily require a change of wheel. Within these boundaries there would be no inertia change to take into account.
The turbine mass multiplier is increased until the wastegate opening required to achieve the specified peak torque engine speed falls to exactly zero. At that instant, one can say there is zero wastegate authority - i.e., there is no remaining margin to raise boost and increase torque by closing the wastegate further. However, it should be noted at this point that, in reality, it would be unwise to design for exactly zero wastegate authority at peak torque - some margin should be introduced to allow for non-ideal wastegate operation (due to wear of the wastegate mechanism, or imperfect seating of the wastegate valve, for example). The situations described in this paper are assumed to benefit from ideal wastegate operation and, though important, do not account for such real-world issues.

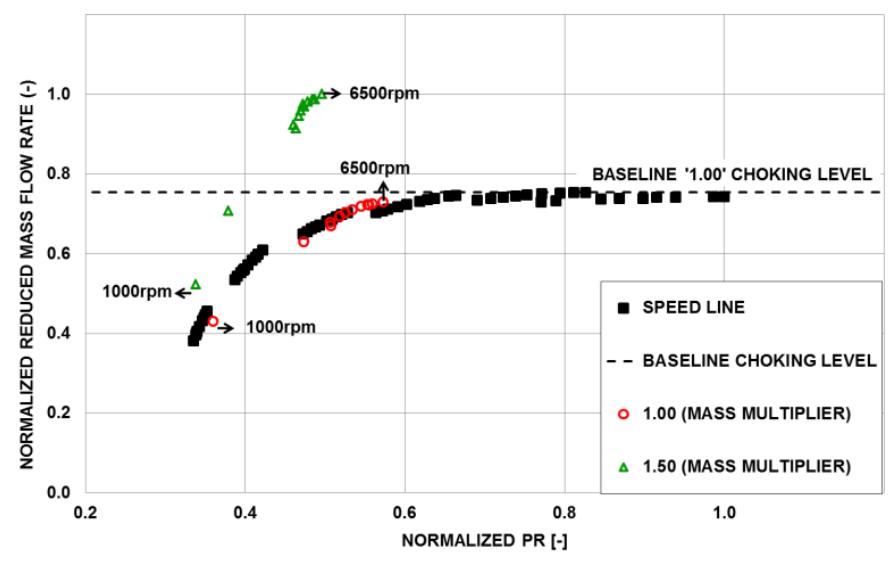

Figure 5. Engine operation plotted on the baseline turbine map for 1.0 and 1.5 mass multipliers.

The peak torque target of the Proton 1.6L CamPro CFE engine is approximately $205 \mathrm{Nm}$ at 2000-4000 rpm (Tab. 1). For current era turbocharged passenger car engines it has become fairly common to target a more or less constant peak torque over an engine speed range, in this fashion. This translates to the vehicle having smooth and predictable acceleration (over said speed range), an important factor in the driver experiencing good driveability [24]. Since it is more difficult for the turbocharger to engender peak torque as engine speed decreases (due to the lower specific energy arriving at the turbine), the lower bound of the peak torque range is the speed of interest here (i.e., $2000 \mathrm{rpm}$ ), and at which zero wastegate authority should be initially be set.

Figure 6 shows the point of zero authority at $2000 \mathrm{rpm}$ is reached when the turbine mass multiplier is set to 1.5 (to a tolerance of $\pm 0.01)$. In other words, increasing the mass multiplier beyond this level would mean that the peak torque target cannot be met. 


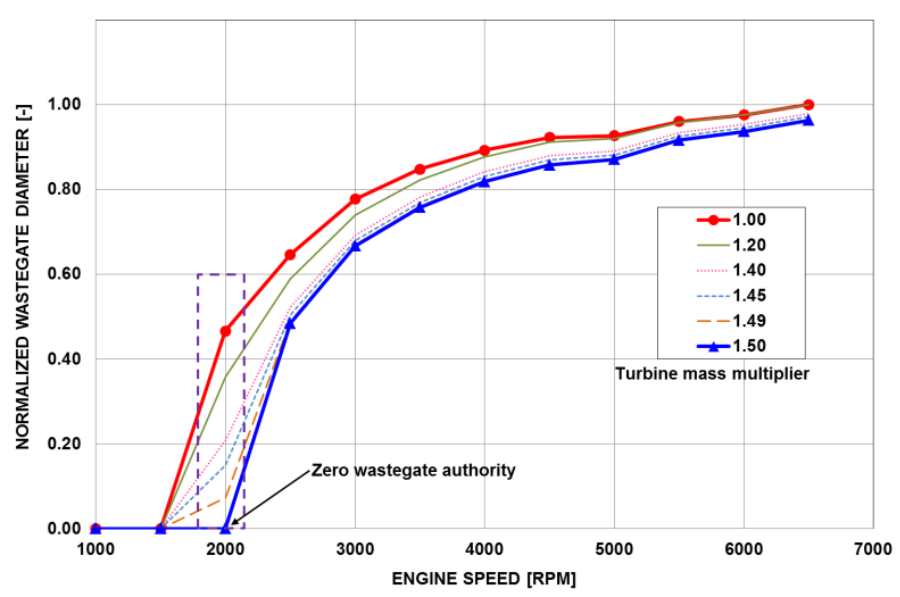

Figure 6. The effect of progressively increasing turbine mass multiplier until there is zero wastegate authority at $2000 \mathrm{rpm}$ (the peak torque speed).

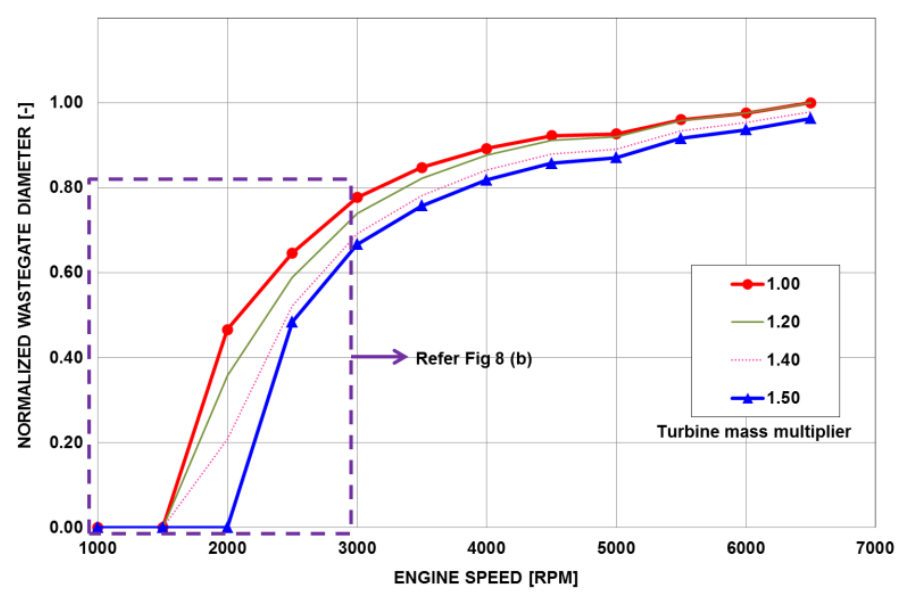

(a)

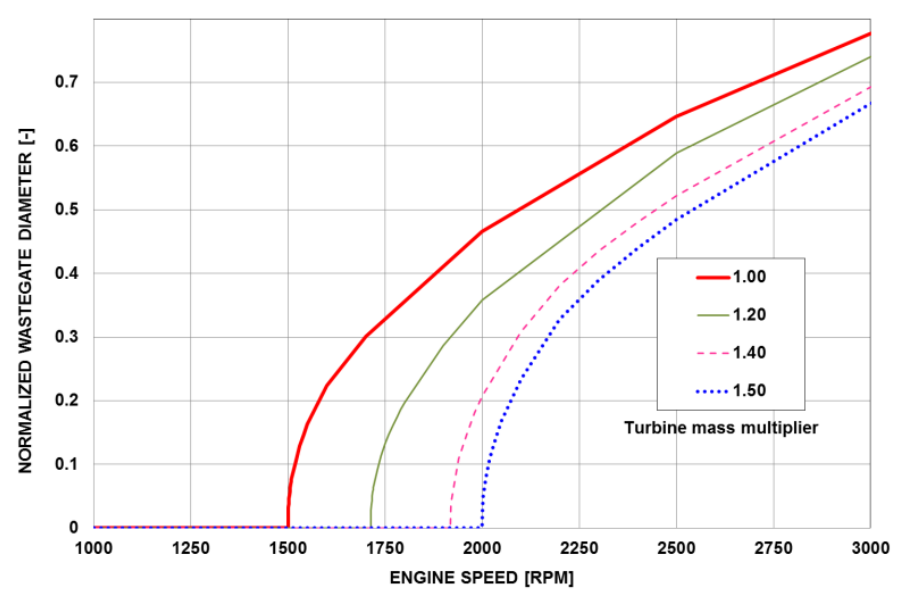

(b)

Figure 7. The effect of turbine mass multiplier on the engine speed at which zero wastegate authority is reached: (a) shows how wastegate diameter falls in discontinuous steps as engine speed reduces (or as mass multiplier increases), while (b) shows how continuous variation of engine speed will identify the zero wastegate authority speed precisely.

A more detailed illustration of zero wastegate authority for different multipliers is presented in Fig. 7. Since the engine simulation is run at discrete speed intervals, the wastegate diameter steps down discontinuously, which is particularly evident at low engine speed in Fig. 7 (a). The precise speed at which zero wastegate authority occurs can be found if the engine speed is allowed to vary continuously, as shown in Fig. 7 (b).

The intended effect of increasing turbine size is to reduce the residual gas trapped in the cylinders. Figures 8 and 9 show the improvement in residuals and the reduction of exhaust pressure at all engine speeds, by increasing the turbine area (via the mass multiplier).

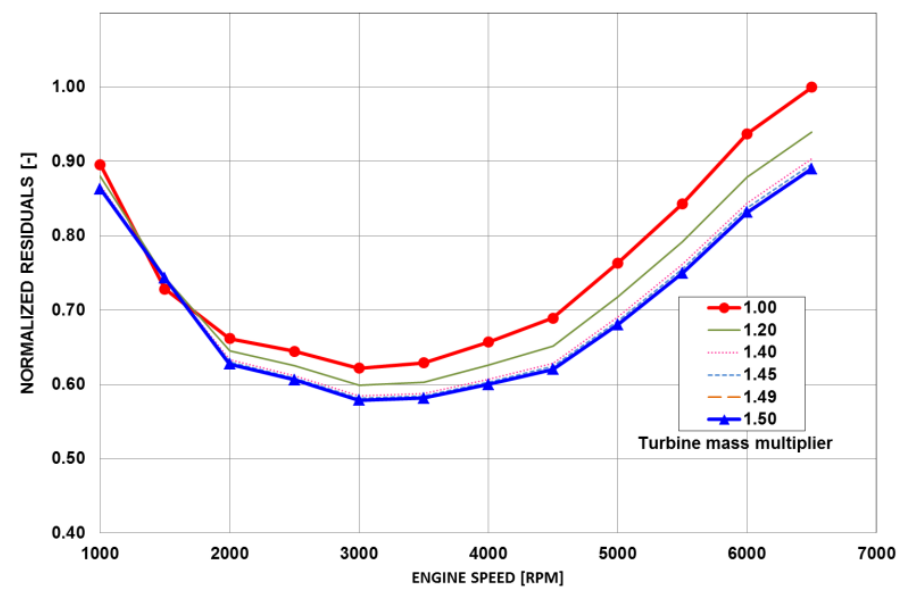

Figure 8. Effect of turbine size on in-cylinder residuals.

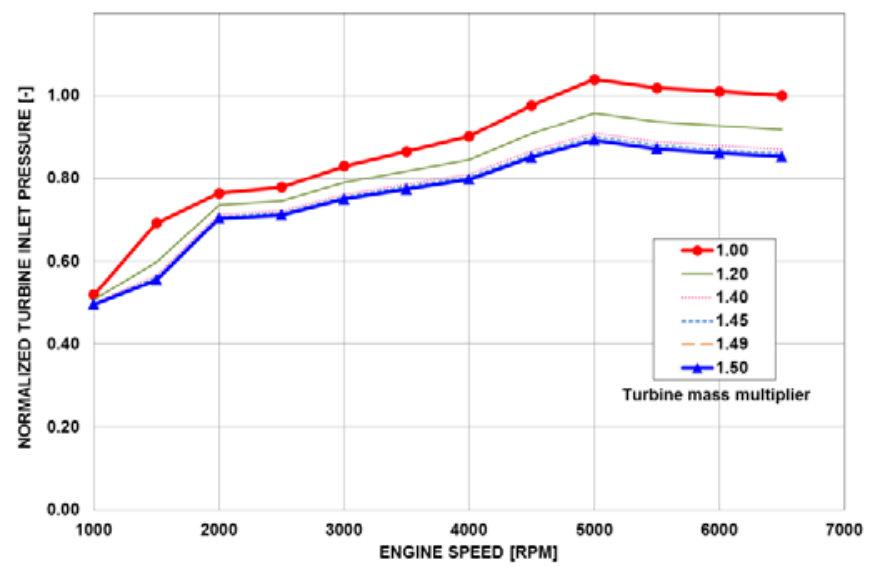

Figure 9. Effect of turbine size on exhaust pressure.

However, Fig. 10(a) shows that the larger (1.5 mass multiplier) turbine causes a clear torque deficit at speeds below $2000 \mathrm{rpm}$, compared to the baseline engine. Although the desired torque at 1500 rpm is much lower than the peak torque, the re-sized turbocharger is unable to provide as much boost as the original here. The brake torque at all engine speeds and the torque deficit at $1500 \mathrm{rpm}$ are presented in Figs. 10 (a) and (b) respectively. This difference would be perceptible to the driver and so a solution for recovering the "lowend" torque is now required.

Page 5 of 9 


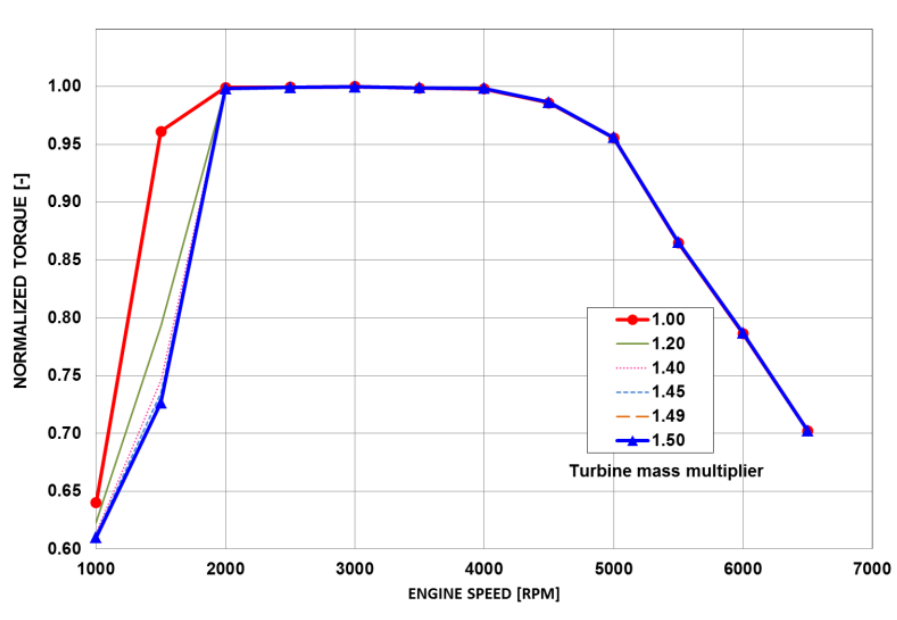

(a)

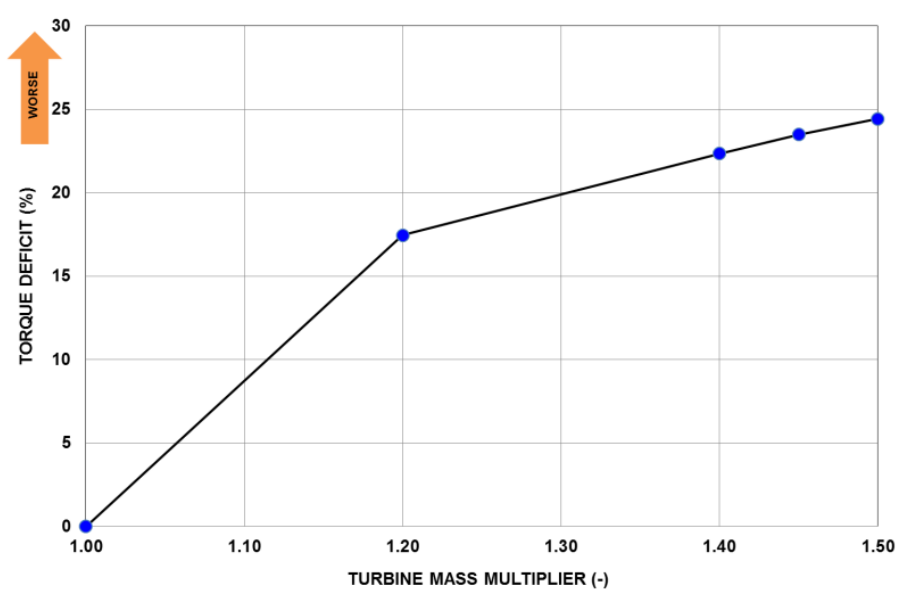

(b)

Figure 10. (a) Brake torque versus engine speed, and (b) torque deficit at 1500 rpm, for different mass multipliers.

To summarize, a larger turbine gives the advantage of reduced back pressure and thus lower residual gas concentration in the engine cylinders, but simultaneously leaves a torque deficit at low engine speeds (e.g., 1000-1800 rpm in the case examined). The next section will explain how such drawbacks can be mitigated by pulse separation.

\section{Pulse Divided Exhaust Manifold}

A new pulse divided exhaust manifold was designed and compared to the standard Proton 1.6L CamPro CFE exhaust manifold (joined manifold), shown earlier in Fig. 3(a). The purpose of a pulse divided exhaust manifold is to isolate the exhaust gas flow arriving from separate groups of cylinders until it reaches the turbine, thereby maintaining pulse energy [4]. In this way, the gas exchange process in one cylinder is not disturbed by pressure pulses emanating from other cylinders. The improved exhaust energy utilization results in improved torque behavior especially at low engine speeds.

Figure 11 shows a 3D CAD model of a pulse divided exhaust manifold design, which combines runner 1 (i.e., the duct connected to the exhaust ports of cylinder 1 ) with runner 4 , while runner 2 is joined with runner 3 . The use of the pulse divided exhaust manifold was then simulated and the compiled results are presented in the next section.

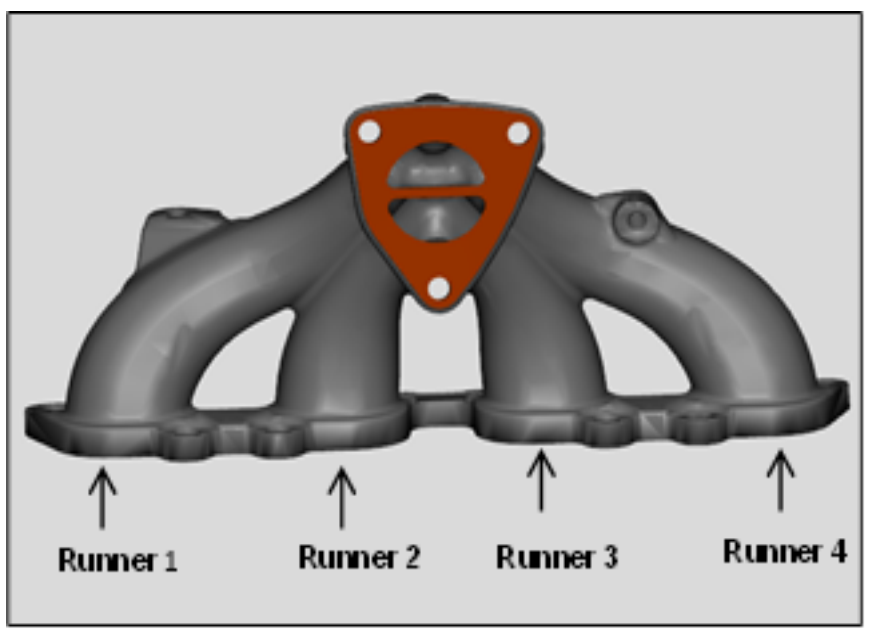

Figure 11. Pulse divided exhaust manifold - 3D CAD model.

\section{Turbine Sizing with Pulse Divided Exhaust Manifold}

A simulation study combining turbine matching and the pulse divided exhaust manifold was carried out to investigate its potential to both preserve exhaust pulse energy and reduce residual gas content. Using the pulse divided manifold, the preserved exhaust pulse energy is substantially higher than that for the standard exhaust manifold and single-entry turbine. As a consequence, exhaust back pressure and the residual gas trapped inside the combustion chamber increased, and so the previously described method of turbine re-sizing was then applied. Table 3 shows the four combinations that were investigated and describes the labels used in Fig. 12.

Table 3. Label descriptions for Figure 12.

\begin{tabular}{|l|l|l|}
\hline Label & Exhaust manifold type & Turbine mass multiplier \\
\hline 1.00 & Joined exhaust manifold (baseline) & 1.00 \\
\hline 1.50 & Joined exhaust manifold & 1.50 \\
\hline PD 1.0 & Pulse divided exhaust manifold & 1.00 \\
\hline PD 2.5 & Pulse divided exhaust manifold & 2.50 \\
\hline
\end{tabular}




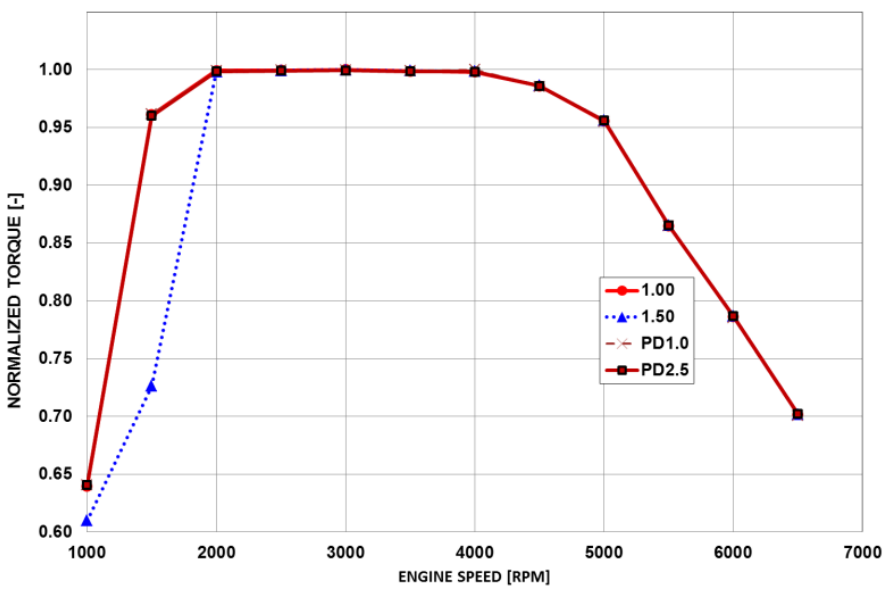

(a)

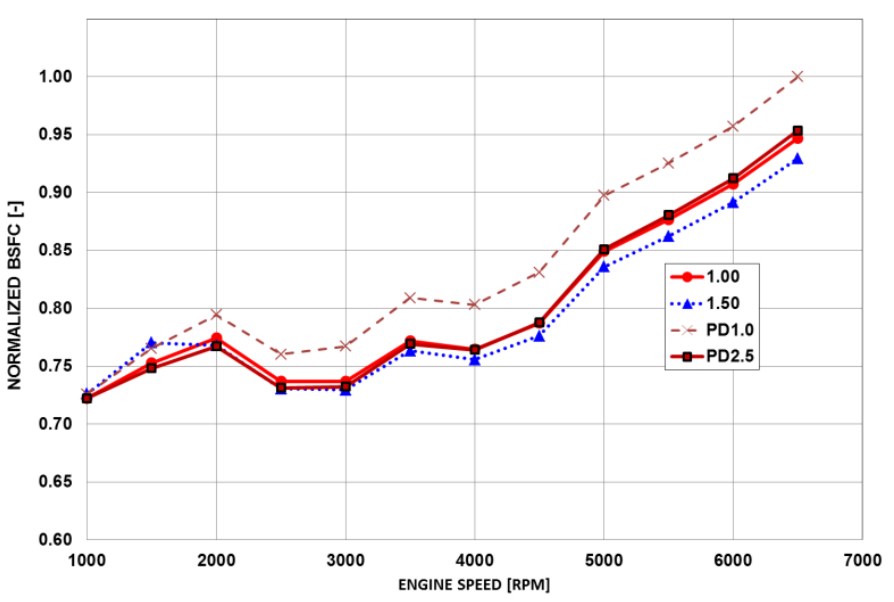

(b)

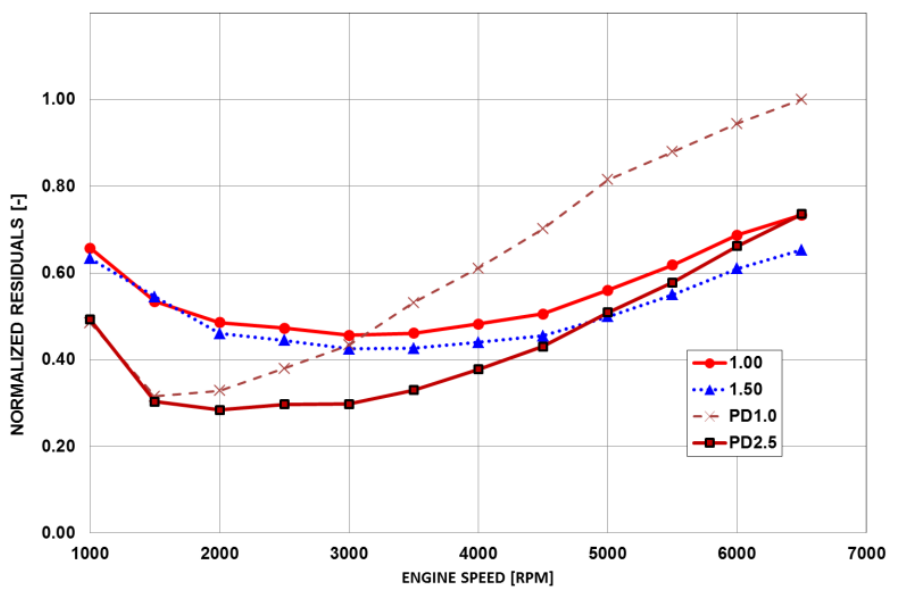

(c)

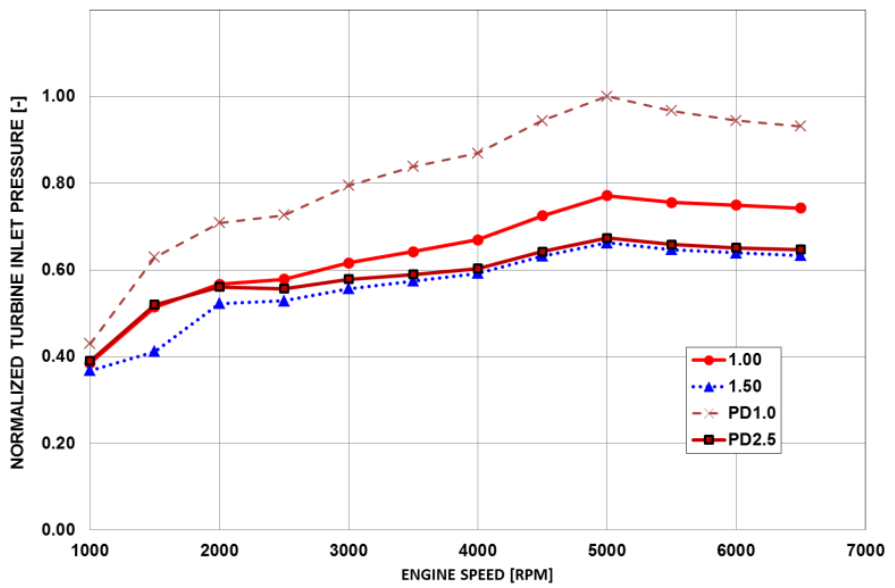

(d)

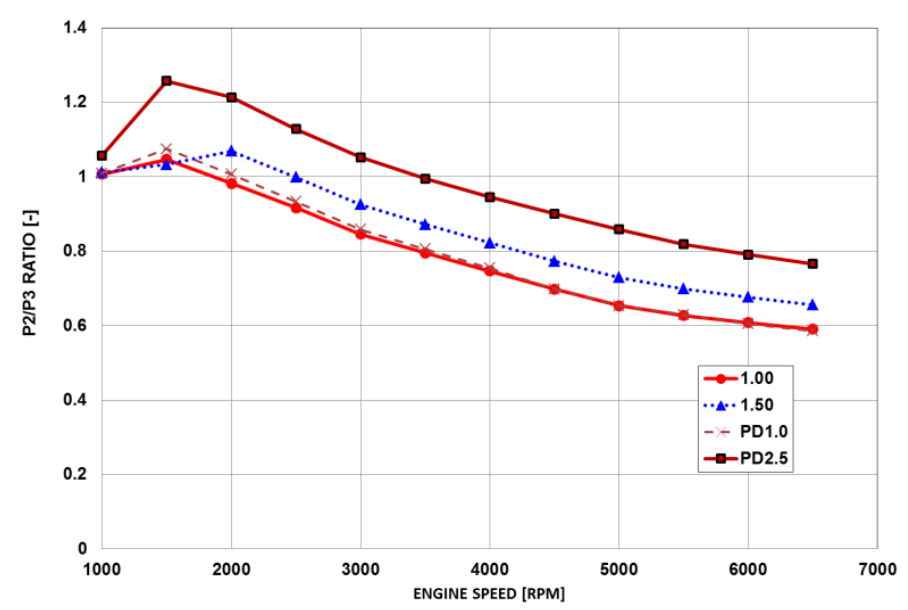

(e)

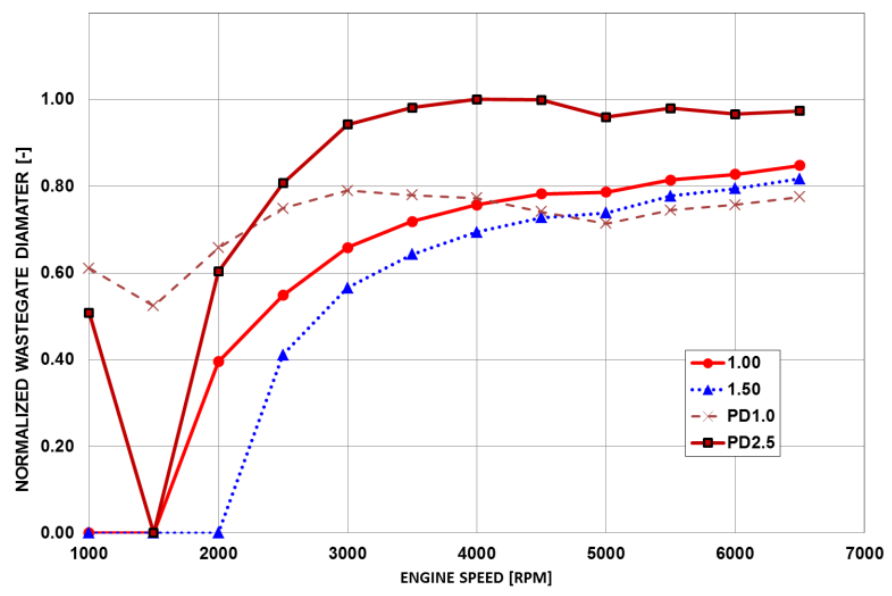

(f)

Page 7 of 9 


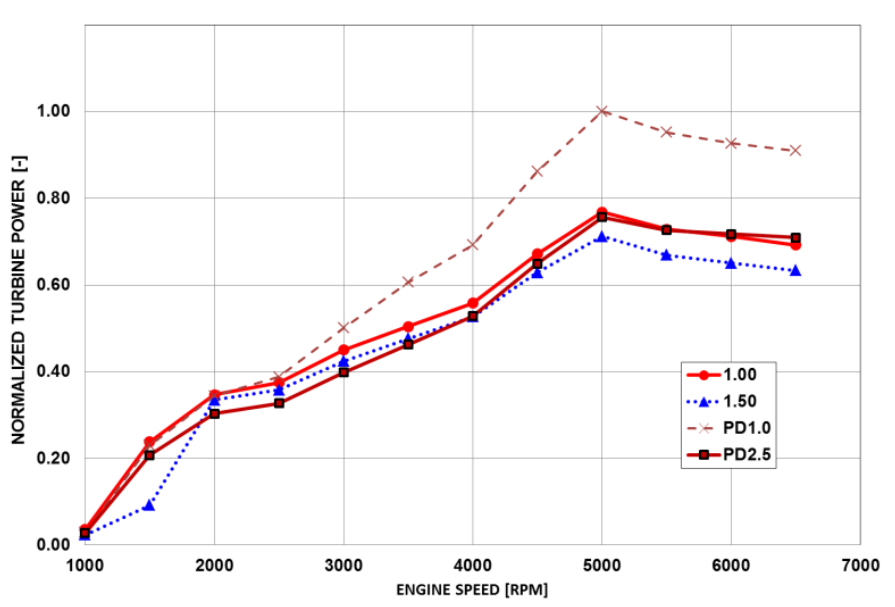

(g)

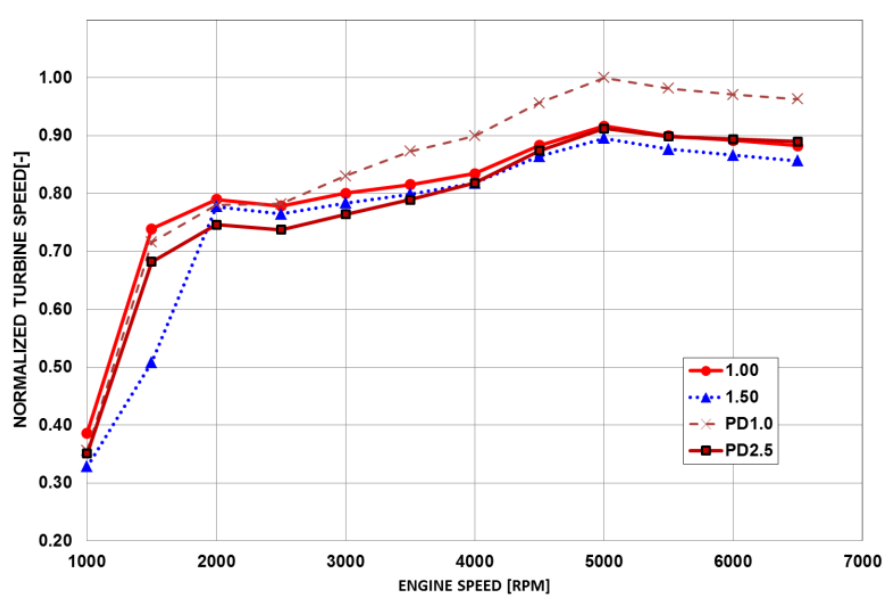

(h)

Figure 12. Turbocharger matching by integrating pulse divided exhaust manifold and turbine re-sizing: (a) brake torque, (b) BSFC, (c) total residual gas content, (d) turbine inlet pressure, (e) scavenging pressure ratio, (f) wastegate diameter, (g) turbine power, and (h) turbine speed.

As shown in Fig. 12 (a), use of the pulse divided manifold (label PD1.0) can easily achieve the torque target at all speeds due to better preservation of exhaust pulse energy entering the turbine, see Fig. 12 (d)). However, this high exhaust pressure causes a significant increase in residual gas content (Fig. 12 (c)). In fact, the use of the pulse divided exhaust manifold will permit the turbine mass multiplier to rise to 2.5, while still maintaining the required torque at low engine speeds (Fig. 12 (a)). Based on simulation results, PD2.5 gives better engine scavenging (Fig. 12 (e)) and this leads to an improvement in residuals of up to $43 \%$ at $1500 \mathrm{rpm}$, compared to the baseline. The result in Fig. 12 (b) shows PD2.5 improves BSFC by approx. $1 \%$ at 1500 rpm compared to the baseline.

\section{Conclusion}

This paper reports a simulation study of the Proton 1.6L CamPro CFE turbocharged gasoline engine using the commercial 1D engine simulation software, GT-POWER. The setup of the model is based on the real engine settings and was successfully validated against experimental test results. A method of turbocharger matching by

Page 8 of 9 integrating pulse separation with turbine matching is proposed. A new pulse divided exhaust manifold is designed to preserve exhaust energy entering the turbine, thus improving torque behavior especially at low engine speeds. The turbine is then re-sized larger in order to reduce exhaust back pressure and the in-cylinder residual gas concentration (with associated benefits for knock). By using a pulse divided exhaust manifold and by increasing the turbine size by a factor of 2.5, improved engine scavenging reduces the residual gas content by up to $43 \%$, BSFC can be improved by approximately $1 \%$, while meeting the steady state torque target of the baseline engine.

In this study, the main parameters of the engine were kept unchanged to keep investigation complexity to a minimum; the choice of compressor was also unchanged. The intention of this work was to explore how a new matching could be estimated without recourse to real map data, in this case by using the mass multiplier. While this is indeed an over-simplified approach in terms of a real matching, the mass multiplier method allows a continuous matching approach without recourse to discrete maps. This would be used to narrow down the search, after which a smaller selection of real maps could be applied to fine tune the match (including the effects of efficiency changes that are not effected by using the mass multiplier).

In practice, re-sizing the turbine will eventually require a larger compressor for reasons of rotordynamics and to ensure both wheels have similar maximum speeds. Another simplification that has not yet been investigated is the change in turbine rotational inertia that will occur once the size change is beyond that which can be achieved by modifying the turbine housing $\mathrm{A} / \mathrm{R}$. The results shown here do not allow for inertia increases, which will directly delay transient response. As such the prediction for PD2.5 in particular must be treated as optimistic and must be simulated again once an accurate estimation of its inertia can be made. This is one area in which real turbine maps (where the corresponding inertia is known) have an advantage. However, one aspect in which a typical turbine map does not offer a complete description is the aforementioned effect of wastgegate flow on turbine swallowing capacity. This is particularly relevant for the sizing methodology described herein which initially establishes turbine size by identifying the point of zero wastegate authority; this issue will be considered in future work.

Furthermore, this study has only considered engine performance at full-load conditions. Future work should also include the optimization of engine parameters such as the valve train and ignition timing, and an assessment of steady state and transient performance under part-load conditions. The potential for increasing compression ratio and thus for further gains in fuel efficiency using this architecture should also be investigated, but more careful attention to the effect on the propensity for knock would be required. Nevertheless, this paper has reported a turbocharger matching method that shows appropriate turbine sizing combined with a pulse divided exhaust manifold can reduce in-cylinder residual concentration and improve fuel consumption, while maintaining the same engine performance.

\section{References}

1. Smokers, R., Vermeulen, R., van Mieghem, R., Gense, R., et al., "Review and analysis of the reduction potential and costs of technological and other measures to reduce $\mathrm{CO}_{2}$-emissions from passenger cars," Final Report, various organizations, Contract nr. SI2.408212, October 2006. 
2. Hardcastle, J., “Automotive Council Technology Work Groups Consensus Roadmaps and Workstream Feedback," Presentation at Low Carbon Vehicle Event, September 2013.

3. Edwards, K., Wagner, R., Briggs, T., and Theiss, T., "Defining Engine Efficiency Limits”, in Proc. 17th DEER Conference, Detroit, USA, October 2011.

4. Pagot, A., Duparchy, A., Gautrot, X., Leduc, P. et al., "Combustion Approach for Downsizing: the IFP Concept," Oil \& Gas Science and Technology - Revue d'IFP Energies nouvelles 61(1):139-153, 2006.

5. Watson, N. and Janota, M. S., Turbocharging the Internal Combustion Engine, The Macmillan Press Ltd, 1982.

6. Heywood, J.B., Internal Combustion Engine Fundamentals, McGraw-Hill, New York, 1988.

7. Tancrez, M., Galindo, J., Guardiola, C., Fajardo, P. et al., "Turbine Adapted Maps for Turbocharger Engine Matching," Experimental Thermal and Fluid Science 35(1):146-153, 2011, doi:10.1016/j.expthermflusci.2010.07.018.

8. Pohorelsky, L., Brynych, P., Macek, J., Vallaude, P.-Y., et al., “Air System Conception for a Downsized Two-Stroke Diesel Engine,” SAE Technical Paper 2012-01-0831, 2012, doi:10.4271/2012-01-0831.

9. Moraal, P., "Turbocharger Modeling for Automotive Control Applications,” SAE Technical Paper 1999-01-0908, 1999, doi:10.4271/1999-01-0908.

10. Korakianitis, T. and Sadoi, T., "Turbocharger-Design Effects on Gasoline-Engine Performance,” J. Eng. Gas Turbines Power 127(3):525-530, 2005, doi:10.1115/1.1808428.

11. Galliot, F., Cheng, W. K., Cheng, C.-O., Sztenderowicz, M., et al., "In-Cylinder Measurements of Residual Gas Concentration in a Spark Ignition Engine”, SAE Technical Paper 900485, 1990, doi: $10.4271 / 900485$.

12. Fox, J. W., Cheng, W. K., and Heywood, J. B., "A Model for Predicting Residual Gas Fraction in Spark-Ignition Engines," SAE Technical Paper 931025, 1993, doi:10.4271/931025.

13. Westin, F., Grandin, B., and Ångström, H., "The Influence of Residual Gases on Knock in Turbocharged SI-Engines,” SAE Technical Paper 2000-01-2840, 2000, doi:10.4271/2000-01$\underline{2840}$.

14. Möller, C. E., Johansson, P., and Grandin, B., "Divided Exhaust Period - A Gas Exchange System for Turbocharged SI Engines,” SAE Technical Paper 2005-01-1150, 2005, doi:10.4271/2005-01-1150.

15. Gundmalm, S., "Divided Exhaust Period on Heavy-Duty Diesel Engines,” Licentiate thesis, Royal Institute of Technology, Stockholm, 2013.

16. Aghaali, H. and Angstrom, H.-E., “The Exhaust Energy Utilization of a Turbocompound Engine Combined with Divided Exhaust Period,” in Proc. IMechE Int. Conf. on Turbochargers and Turbocharging, pp 179-188, 2014.

17. Hu, B., Brace, C., Akehurst, S., Copeland, C., et al., "The Effect of Divided Exhaust Period for Improved Performance in a Highly Downsized Turbocharged Gasoline Engine,” in Proc. IMechE Int. Conf. on Turbochargers and Turbocharging, pp 2739, 2014.

18. Roth, D., Keller, P., Sisson, J., and Tec, B. M., "Valve-Event Modulated Boost System,” SAE Technical Paper 2010-01-1222, 2010, doi:10.4271/2010-01-1222.

19. Roth, D. B. and Becker, M., "Valve-Event Modulated Boost System: Fuel Consumption and Performance with ScavengeSourced EGR,” SAE Technical Paper 2012-01-0705, 2012, doi:10.4271/2012-01-0705.

20. Gamma-Technologies Inc., GT-SUITE Flow Theory Manual, V 7.1, 2010.

Page 9 of 9
21. Woollenweber, W., "The Turbocharger - A Vital Part of the Engine Intake and Exhaust Systems," SAE Technical Paper 700534, 1970, doi:10.4271/700534.

22. Capobianco, M. and Polidori, F., "Experimental Investigation on Open Waste-Gate Behaviour of Automotive Turbochargers," SAE Technical Paper 2008-36-0052, 2008, doi:10.4271/200836-0052.

23. Marelli, S., and Capobianco, M., "Steady and Pulsating Flow Efficiency of a Waste-gated Turbocharger Radial Flow Turbine for Automotive Application,” Energy 36(1):459-465, 2011, doi:10.1016/j.energy.2010.10.019.

24. Wicke, V., Brace, C. J., Deacon, M., and Vaughan, N. D., "Preliminary Results from Driveability Investigations of Vehicles with Continuously Variable Transmissions," In Proceedings of CVT'99, Eindhoven University of Technology, September 16-17, 1999.

\section{Contact Information}

Dr Aaron Costall

Imperial College London

Department of Mechanical Engineering

South Kensington Campus

London SW7 2AZ

United Kingdom

Email: a.costall@imperial.ac.uk

\section{Acknowledgments}

The authors would like to thank Perusahaan Otomobil Nasional Sdn Bhd (PROTON) for providing the experimental test results and their assistance during the baseline engine validation activity.

\section{Definitions/Abbreviations}

$\begin{array}{ll}\text { BSFC } & \text { Brake specific fuel consumption } \\ \text { BTDC } & \text { Before top dead center } \\ \text { CAD } & \begin{array}{l}\text { Crank angle degrees, computer aided } \\ \text { design }\end{array} \\ \text { DEP } & \text { Divided Exhaust Period } \\ \text { PD } & \text { Pulse divided } \\ \text { PFI } & \text { Port fuel injection } \\ \text { SI } & \text { Spark ignition } \\ \text { TDC } & \text { Top dead center } \\ \text { VEMB } & \text { Valve-Event Modulated Boost } \\ \text { WOT } & \text { Wide open throttle }\end{array}$

